DOI: 10.12731/wsd-2018-4-245-257

УДК 599:539.1.047

\title{
ОЦЕНКА ЭФФЕКТИВНОСТИ ЭКСТPAКTA HALOCYNTHIA AURANTIUM ПРИ ЭКСПЕРИМЕНТАЛЬНОМ ЛУЧЕВОМ ПОРАЖЕНИИ
}

\section{Пономарева Т.И.}

Проведено исследование лечебного эффекта экстракта из морского гидробионта Halocynthia aurantium при радиационном воздействии. Экстракт асиидии (ЭА) содержит комплекс биологически активных веществ и обладает способностью повышать неспецифическую резистентность организма к действию ряда экстремальных повреждающих факторов.

Объектом исследования являлись мыши $B A L B / c$ подвергнутые $\gamma$-облучению излучением малой мощности.

Цель работы состояла в оиенке лечебного влияния ЭА на пострадиационную динамику показателей периферической крови и клеточность костного мозга (доза 5 Гр) и на исход радиаџионного поражения (доза 13 Гр). ЭА животные получали ежедневно в течение всего эксперимента, начиная в день окончания облучения.

Методика взятия материала и анализ элементов периферической крови и костного мозга стандартная. Показано, что в ранние сроки после облучения наблюдалось резкое снижение общего числа лейкочитов периферической крови и ядросодержащих клеток в костном мозге. Ежедневное применение ЭА способствовало ускорению восстановления клеточного состава костного мозга и увеличению общего числа лейкочитов и тромбоцитов в периферической крови.

Можно заключить, что применение ЭА после радиачионного воздействия позволило существенно повысить вероятность благоприятного исхода острой лучевой болезни при дозе облучения 5 Гр и облегчить ее течение.

Ключевые слова: радиационное воздействие; экстракт асцидии Halocynthia aurantium; лейкоциты; тромбоциты; постлучевая регенерация костного мозга; средняя продолжительность жизни. 


\section{EVALUATION OF EFFECTIVENESS OF HALOCYNTHIA AURANTIUM EXTRACT AT EXPERIMENTAL RAY IMPACT}

\section{Ponomareva T.I.}

The effect of the extract from the marine hydrobiont Halocynthia aurantium (EA) under radiation exposure was studied. EA contains a complex of biologically active substances and has the ability to increase the nonspecific resistance of the organism to the action of a number of extreme damaging factors.

The object of the study was the BALB/c mice subjected to $\gamma$-irradiation with low-power radiation.

The aim of the work was to evaluate the therapeutic effect of EA on the post-radiation dynamics of peripheral blood parameters and bone marrow cellularity (dose $5 \mathrm{~Gy}$ ) and on the outcome of radiation damage (dose $13 \mathrm{~Gy}$ ). $E A$ animals were received daily throughout the experiment, starting on the day of irradiation termination.

The method of taking the material and analyzing elements of peripheral blood and bone marrow is standard. There was shown that in the early periods after irradiation, a sharp decrease in the total number of peripheral blood leukocytes and nucleated cells in the bone marrow was observed. The daily use of EA contributed to the acceleration of bone marrow cell repair and an increase in the total number of leukocytes and platelets in the peripheral blood. It can be concluded that the use of EA after radiation exposure has significantly increased the probability of a favorable outcome of acute radiation sickness at a dose of 5 Gy and to facilitate its course.

Keywords: radiation impact; extract of ascidia Halocynthia aurantium; leukocytes; platelets; bone marrow regeneration.

В последние годы значительно возросло внимание специалистов к действию на организм ионизирующей радиации малой мощности. Особый интерес к малым дозам облучения обусловлен проблемами радиоэкологии, хронического облучения, последствий радиационных аварий и профессионального контакта с источниками излучения. В результате многочисленных исследований получены достоверные сведения о поражении организма при протяженном облучении и накоплен экспериментальный и клинический материал, свидетельствующий о возможности 
снижения радиочувствительности подопытных животных и человека при помощи химических и биологических агентов [1, с. 287; 2, с. 475; 3, с. 513]. Однако, несмотря на определенные успехи в создании противолучевых препаратов, снижающих проявления радиационного поражения организма, нужда в медикаментозных средствах, применяемых после облучения, вводимых с лечебно-восстановительной целью, сохраняется. Перспективными в этом плане являются вещества, обладающие антиоксидантными свойствами, с эффектами повышения пролиферативной активности и неспецифической резистентности с вовлечением иммунной системы $[4$, с. $87 ; 5$, с. 348$]$. С этой точки зрения представляют интерес препараты природного происхождения с высокой фармако-физиологической активностью и возможностью длительного применения. В последние десятилетия внимание исследователей привлекают морские биологические ресурсы, отдельные представители которых являются богатым источником биологически активных веществ [6, с. 17; 7, с. 457; 8, с. 64]. Экстракт из морского гидробионта асцидии пурпурной Halocynthia aurantium получен и охарактеризован в отделе биохимических технологий Тихоокеанского океанологического института (ТОИ) ДВО РАН. Экстракт асцидии (ЭА) повышает неспецифическую резистентность организма к действию ряда экстремальных повреждающих факторов, таких как физические нагрузки, гипоксия, интоксикации (аутоинтоксикация, четыреххлористый углерод, гексенал, этанол) [9, с. 637]. Стресс-протективный эффект ЭА связан с влиянием на метаболические процессы [10, с. 25]. Показана его способность ингибировать свободнорадикальные процессы, усиливая активность глутатионзависимых механизмов антиоксидантной защиты [11, c. 85], восстанавливать соотношение липидных компонентов клеточной мембраны при стресс-воздействии и действии токсических веществ [10, c. $25 ; 12$, с. 28], что может сыграть позитивную роль в модификации радиационно-химических поражений. Помимо отмеченных свойств данный экстракт не проявляет токсических эффектов и безвреден при длительном применении [13, с. 908]. Широкий спектр фармакологической активности ЭА обеспечивается многокомпонентностью его составляющих, среди которых фосфолипиды, аминокислоты, полиненасыщенные жирные кислоты, макро- и микроэлементы и др. [12, с. 28; 14, с. 151].

Целью работы являлось изучение лечебного эффекта экстракта из морского гидробионта Halocynthia aurantium (ЭА) на выживание и гемопоэз мышей в условиях пролонгированного $\gamma$-облучения излучением малой мощности. 


\section{Материалы и методы}

Эксперименты выполнены на 130 мышах-самцах линии BALB/c («Столбовая»), массой тела 18-21 г в возрасте 2 мес. Животных содержали в клетках по 10 особей при температуре $22^{0}$ и естественном световом режиме, в условиях свободного передвижения и доступа к воде и стандартному гранулированному корму. Мышей подвергали $\gamma$-облучению на установке ГУБЭ 400 с циркуляторным расположением стержня радиоцезия ${ }^{137} \mathrm{Cs}$, мощность дозы 0,0067 Гр/мин, при равномерности поля облучения животных $\pm 5 \%$. Мощность дозы и дозовое распределение контролировали используя дозиметрические приборы типа «27.012.» (Германия). ЭА комплекс биологически активных веществ, основными структурными компонентами которого являются фосфолипиды, свободные аминокислоты, полиненасыщенные жирные кислоты n-3, n-6, каротиноиды, простагландины [14, с. 151]. В каждой серии было сформировано по две группы животных - опытная, получающая лечение экстрактом, и контрольная. ЭА вводили животным ежедневно перорально в дозе 1/100 ЛД ответствует 35 мг/кг сухого остатка) в течение всего эксперимента по 0,2 мл, первое введение через 15 мин после окончания облучения. Контрольные животные получали аналогично дистиллированную воду (облученный контроль). Показателями терапевтической активности экстракта при дозе 13 Гр (время воздействия 32 ч 20 мин) служили 30-суточное выживание, средняя продолжительность жизни (СПЖ) погибших животных, гибель животных по фазам лучевой болезни (в группах по 20 особей). Влияние ЭА на гемопоэз исследовали на мышах, подвергнутых $\gamma$-облучению в дозе 5,0 Гр (время экспозиции 12 ч 20 мин).По окончании облучения были сформированы 2 группы по 40 особей. Обследование подопытных и контрольных животных проводили в одни и те же сроки: до начала и после радиационного воздействия на 3-е, 7-е, 9-е, 14-е сутки (по 10 животных из каждой группы). Прослеживали пострадиационную динамику показателей периферической крови (лейкоциты, тромбоциты), клеточность и морфологический состав костного мозга (бедро), учитывали массу животных и лимфоидных органов (тимус, селезенка) [15, с. 235]. Количество эндогенных колоний в селезенке (КОЕс9) [16, с. 172] выявляли после двухчасовой фиксации в жидкости Буена на 9-е сут после облучения.

Эксперименты по влиянию ежедневного перорального введения ЭА (12 сут) на показатели периферической крови, костный мозг и лимфоидные органы проведены на интактных беспатогенных мышах линии CD-1 массой 20-22 г (90 особей), из которых сформированы опытная и контроль- 
ная группы по 45 животных. Мыши получены из питомника лабораторных животных «Пущино» и разведены в виварии Тихоокеанского института биоорганической химии ДВО РАН (сертификат имеется). Материал для исследования брали на 1-9-е, 12-е сут, по 5 особей на каждый срок.

Животных содержали и выводили из эксперимента (декапитацией под легким эфирным наркозом) с соблюдением правил и международных рекомендаций Европейской конвенции по защите позвоночных животных, используемых для экспериментов или в иных научных целях (Страсбург 1986). Протокол исследования согласован с этическим комитетом ТОИ ДВО РАН. Обработку результатов проводили с использованием статистического пакета Instat 3.0 (Graph Pad Software Inc. USA, 2005) с функцией проверки соответствия выборки закону нормального распределения. Для определения статистических различий использовали параметрический $\mathrm{t}$-критерий Стьюдента. Различия считали статистически значимыми при $\mathrm{p}<0,05$.

\section{Результаты и обсуждение}

Показано, что ежедневное введение ЭА интактным мышам в течение 12 сут не влияло на общее состояние и массу животных. Согласно результатам гематологического исследования под влиянием ЭА на 1-е и 8-е сутки общее число лейкоцитов в периферической крови мышей было снижено по сравнению с интактным контролем в 1,5 раза $(\mathrm{p}<0,05)$, а наивысший уровень (в 1,6 раза, $\mathrm{p}<0,05)$ зарегистрирован на 6-е сутки. Соотношения лимфоцитов и нейтрофильных гранулоцитов сохранялись в пределах интактных животных, отражая количественно лишь изменения общего уровня лейкоцитов. Вместе с тем, с 3-их сут, и до конца эксперимента, в 1,5-2 раза была увеличена доля палочкоядерных форм нейтрофилов. Численность эритроцитов и тромбоцитов не претерпевала существенных изменений. Наблюдалась тенденция к увеличению клеток миелоидного ряда костного мозга, а, в общем, изменения в содержании миелокариоцитов костного мозга не выходили за пределы значений интактных животных, также как и общая численность спленоцитов. Таким образом, отмеченные изменения носят, по всей вероятности, адаптационный характер, и согласуются с мнением, что средства с адаптогенными свойствами, к которым относится и ЭА, действуют в организме, как правило, в условиях нарушенных функций [9, с. 637; 13, с. 908; 17, с. 1057].

Радиационное воздействие в дозе 13 Гр привело к развитию тяжелой формы лучевой болезни, завершившейся гибелью подавляющего большинства животных в течение 30 сут. Известно, что при пролонгированном облучении 
излучением невысокой интенсивности развивается патологический процесс, в основных чертах сходный с лучевым поражением в условиях кратковременного воздействия интенсивных доз радиации $[18$, с. $122 ; 19$, с. 420$]$. К числу особенностей, этого вида радиационного поражения относится слабая выраженность кишечного синдрома. Анализ течения лучевой болезни мышей по фазам свидетельствует, что животные, получавшие ЭА, равно как и контрольные, пережили первые сутки после радиационного поражения без отягощения кишечным синдромом. Пик смертности переместился на период костномозговых нарушений (8-13-е сут), когда пало большинство животных: решающим в исходе заболевания явилось нарушение гемопоэза. К 30 суткам в контрольной группе выжили $25 \%$ мышей, а в экспериментальной $35 \%$. Вместе с тем, СПЖ погибших мышей в контрольной группе составила 9 сут, а под влиянием ЭА - 13 сут. Таким образом, ЭА не оказывал существенного влияния на 30-суточное выживание мышей облученных в дозе 13 Гр, но способствовал увеличению средней продолжительности их жизни.

Результаты влияния ЭА на гемопоэз животных, подвергнутых $\gamma$-облучению в дозе 5,0 Гр, представлены в таблице. Выживание животных сопровождалось выраженной лейкопенией: численность лейкоцитов на 3 сут снижалась на $80 \%$ от интактных значений в обеих группах. Однако к 7 суткам общее количество лейкоцитов под влиянием экстракта в 2 раза $(\mathrm{p}<0,05)$ превышало уровень контрольных животных, в дальнейшем восстановление этого показателя также шло опережающими темпами.

Таблиияа.

Изменения лейкоцитов, тромбоцитов, миелокариоцитов мышей BALB/c, подвергнутых пролонгированному $\gamma$-облучению (доза 5 Гр) и под влиянием экстракта Halocynthia aurantium $(\mathrm{M} \pm \mathbf{m})$

\begin{tabular}{|c|c|c|}
\hline \multirow{2}{*}{$\begin{array}{c}\text { Показатели } \\
\text { Сроки после } \\
\text { облучения }\end{array}$} & \multicolumn{2}{|c|}{$\begin{array}{c}\text { Лейкоциты } 10^{9} / \text { л } \\
\text { Тромбоциты } 10^{9} / \text { л } \\
\text { Миелокариоциты } 10^{6} / \text { мл }\end{array}$} \\
\cline { 2 - 3 } & Облучение + экстракт & Облучение (контроль) \\
\hline \multirow{2}{*}{ До } & \multicolumn{2}{|c|}{$13,7 \pm 2,0$} \\
облучения & \multicolumn{2}{|c|}{$646 \pm 10,80$} \\
\hline \multirow{2}{*}{3 сут } & $2,26 \pm 0,24$ & $2,69 \pm 0,84$ \\
& $520,0 \pm 11,70$ & $516,0 \pm 9,10$ \\
& $2,12 \pm 0,19$ & $2,30 \pm 0,17$ \\
\hline \multirow{2}{*}{7 сут } & $4,45 \pm 0,31^{*}$ & $332,0 \pm 0,25$ \\
& $419,0 \pm 10,30$ & $3,24 \pm 0,34$ \\
\hline
\end{tabular}




\begin{tabular}{|c|c|c|}
\hline \multicolumn{3}{|c|}{} \\
\hline \multirow{3}{*}{10 сут } & $6,30 \pm 0,46^{*}$ & Окончание табл. \\
& $471,0 \pm 10,51^{*}$ & $2580 \pm 0,30$ \\
& $10,07 \pm 0,48^{*}$ & $5,93 \pm 0,32$ \\
\hline \multirow{3}{*}{14 сут } & $12,06 \pm, 37^{*}$ & $8,72 \pm 0,45$ \\
& $490,0 \pm 9,17$ & $500,0 \pm 12,6$ \\
& $9,50 \pm 0,69$ & $9,54 \pm 0,26$ \\
\hline
\end{tabular}

Примечание: * - $<0,05$ по сравнению с группой облученного контроля

Аналогичная картина наблюдалась в отношении лимфоцитов и, наиболее выраженно, нейтрофильных гранулоцитов. Снижение числа тромбоцитов было менее выражено в группе леченых мышей, и восстановление начиналось раньше. Заслуживают внимания данные по динамике миелокариоцитов трубчатых костей облученных животных. Показано, что по клеточности костного мозга в первые сутки поражения экспериментальные и контрольные животные не отличались между собой. Вместе с тем, благоприятное действие ЭА на процесс регенерации гемопоэза отчетливо прослеживалось в период между 7-10-ми сутками, когда уровни миелокариоцитов у леченых животных превышали контрольные значения в $1,7-2$ раза $(\mathrm{p}<0,05)$, за счет увеличения клеток миелоидного ряда. С учётом времени, необходимого для восстановления популяций стволовых клеток гемопоэза после облучения, а также продвижения их потомков до состояния функционально зрелых клеток, можно сделать вывод, что эффекты ЭА относятся к пролиферирующему пулу гемопоэза. Возможна также и активация процессов постлучевой репарации с возвращением «в строй» части гемопоэтических клеток [2, с. 475; 20, с. 607]. Известно, что исход поражения при радиационном воздействии на организм определяется, как степенью угнетения гемопоэза, так и способностью кроветворной ткани к постлучевой регенерации $[1$, с. $287 ; 18$, с. $122 ; 19$, с. 420]. Классическим тестом для анализа противолучевой активности фармакологических препаратов является селезеночный эндоколониальный метод, когда на фоне постлучевого опустошения в селезенке формируются колонии из потомков выживших стволовых гемопоэтических клеток [2, c. $475 ; 3$, с. $513 ; 16$, с. 172]. Показано, что количество эндогенных колоний в селезенке на 9-е сут под влиянием ЭА в 2 раза превышало значения контрольных животных $(14,1 \pm 3,2$ против $7,3 \pm 3,0$ в контроле, $\mathrm{p}<0,05)$. Масса селезенки при этом была увеличена недостоверно (в 1,2 раза). Исходя их того, что степень опустошения костного мозга в эксперименте в первые сутки после облучения в обеих группах была одинаковой, можно 
заключить, что действие ЭА адресовано одной из критических тканей кроветворной и реализуется на уровне стволовых кроветворных клеток, ускоряя начало и темпы восстановления гемопоэза.

Разумеется, экспериментальный материал недостаточен для того, чтобы количественно оценить терапевтическую активность и объяснить механизм действия ЭА. Исследуемый экстракт асцидии по своим свойствам относится к средствам, для которых известна способность действовать в различных направлениях в зависимости от физиологического фона [9, c. $637 ; 10$, с. $25 ; 13$, с. 50]. ЭА представляет собой композицию природных веществ, биологические свойства которых могут дополнять друг друга. Так, жирнокислотный состав фосфолипидов экстракта асцидии отличается высокой степенью ненасыщенности и содержит в своем составе полиненасыщенные жирные кислоты семейства n-3, n-6 необходимые для преобразования лизофосфолипидов в основные структурные компоненты мембран $[10$, с. $25 ; 14$, с. 151$]$. Каротиноиды же, входящие в состав экстракта, обладают антиоксидантной и мембранотропной активностью, способны связываться с фосфолипидами и стабилизировать структуру мембран $[11$, с. $85 ; 12$, с. 28$]$. Аминокислоты могут быть охарактеризованы как стимуляторы регенерации [20, с. 607; 21, с. 129]. Кроме того, следует отметить, что для ЭА показана генопротекторная активность [22, с. 63], это качество может оказаться весьма полезным, поскольку известно, что радиационные воздействия помимо ранних негативных эффектов, опасны также и отдаленными последствиями [1, с. 287; 7, с.457; 18, с. 122], определяющее значение в которых принадлежит генетическому аппарату клетки.

\section{Заключение}

Таким образом, показана определенная позитивная активность экстракта асцидии Halocynthia aurantium при поражении организма радиацией малой мощности. Выраженность лечебного эффекта экстракта увеличивается со снижением дозы облучения. Одним из механизмов, лежащих в основе лечебного эффекта ЭА, по нашему мнению, является активация под его влиянием пролиферации и дифференцировки стволовых кроветворных клеток, сохранившихся в костном мозге облученных мышей. ЭА обладает рядом преимуществ по сравнению с классическими синтетическими радиопротекторами, особенно важных в условиях длительной дозовой нагрузки и соответственно необходимости его длительного применения. Прежде всего, у него отсутствуют токсичность и другие побочные отрицательные влияния на организм. Попадая в организм после образования в 
биосубстрате первичных физико-химических повреждений, вызванных радиационным воздействием, ЭА, по-видимому, создает благоприятный фон для мобилизации резервов, сохранившихся в результате облучения, стимулируя регенеративные процессы в кроветворной системе, и уменьшая тяжесть лучевой болезни. Представленные результаты предполагают необходимость дальнейшего изучения ЭА как в качестве радиомодулятора, так и средства лечения ранних стадий костномозгового синдрома.

\section{Благодарности}

Автор выражает благодарность старшему инженеру лаборатории биофизики Стасенко Наталье Яковлевне за помощь в проведении экспериментов.

\section{Список литературы}

1. Баранов А.Е., Рождественский Л.М. Аналитический обзор схем лечения острой лучевой болезни, используемых в эксперименте и клинике // Радиационная биология. Радиоэкология. 2008. Т.48, № 3. С. 287-302.

2. Модификация радиационных эффектов влияние последовательного применения препарата Б-190 и интерлейкина- $1 \beta$ на выживаемость и костномозговое кроветворение облученных мышей / Гребенюк А.Н., Зацепин В.В., Аксенова Н.В., Назаров В.Б., Власенко Т.Н. // Медицина катастроф. 2011. № 4. C. 475-480.

3. Рождественский Л. М. Актуальные вопросы поиска и исследования противолучевых средств // Радиация и риск. 2013. № 5. С. 513-520.

4. Patil S.L., Mallaiah S.H., Patil R.K. Antioxidative and radioprotective potential of rutin and quercetin in swiss albino mice exposed to gamma radiation // $\mathrm{J}$. Med. Phys. 2013. Vol. 38, pp. 87-92.

5. Wang Y., Liu L., Pazhanisamy S.K., Li H., Meng A., Zhou D. Total body irradiation causes residual bone marrow injury by induction of persistent oxidative stress in murine hematopoietic stem cells // Free Radic. Biol. Med. 2010. Vol. 48, pp. 348-356.

6. Browman K, Leong K.W. Chitosan nanoparticles for oral drug and gene delivery // Int. J. Nanomedicine. 2006. no 2, pp. 17-28.

7. Возможности использования защитного действия препарата МИГИ-К в условиях загрязнения местности радионуклидами / Абрамова Л.С., Деев Л.И., Кудряшов Ю.Б., Кудряшова Н. Ю., Пархоменко И. М., Платонов А.Г. // Радиационная биология. Радиоэкология. 2011. Т. 51, № 4. С. 457-463.

8. Янькова В.И., Кнышова В.В., Ланкин В.З. Механизмы коррекции окислительного стресса антиоксидантами из морских гидробионтов при алиментарных дислипидемиях // Бюллетень СО РАМН. 2012. №1. С. 64-69. 
9. Добряков Ю.И., Добряков Е.Ю., Пономарева Т.И. Исследование фармакологических свойств экстракта из морского гидробионта - асцидии пурпурной (Halocynthia aurantium) / Дальневосточные моря России. М.: Наука, 2007. Кн. 2. С. 637-657.

10. Добряков Е.Ю. Фармакологические эффекты экстракта из туники асцидии Halocynthia aurantium.: автореф. дис. ...канд. мед. наук. Владивосток, 2004. 25 с.

11. Долматова Л.С., Долматов И.Ю., Добряков Ю.И. Антиоксидантная и биологическая активность экстрактов голотурии Eupentacta fraudatrix и асцидии Halocynthia aurantium // Мат-лы съезда Фитофарм-2004. СПб: Адаптоген, 2004. C. $85-88$.

12. Исследование иммуномодулирующей и мембранотропной активности каротиноидов из туники асцидии Halocynthia aurantium / Моторя Е.С., Пивненко Т.Н., Гажа А.К., Иванушко Л.А., Воронцов В.Н., Санина Н.М. // Тихоокеанский медицинский журнал. 2009. № 3. С. 28-31.

13. Пономарева Т.И., Добряков Ю.И. Исследование биологической активности экстрактов морских гидробионтов непищевого использования // В мире научных открытий. 2011. № 7.2. С. 908-918.

14. Кушнерова Н.Ф., Добряков Ю.И., Янькова В.И. Химический состав спиртовых извлечений из туники асцидии пурпурной Halocynthia aurantium // Валеология: Диагностика средства и практика обеспечения здоровья. Владивосток: Дальнаука, 2000. С. 151-155.

15. Руководство по гематологии [Под ред. А. И. Воробьева]. М.: Медицина, 2002. $235 \mathrm{c}$.

16. Переверзев А.Е. Кроветворные колониеобразующие клетки и физические стресс-факторы. Л.: Наука, 1986. 172 с.

17. Deyama T., Nishibe S., Nakazawa Y. Constituents and pharmacological effects of Eucommia and Sibirian ginseng // Acta Pharmacol. Sinica. 2011. Vol. 12, pp. 1057-1070.

18. Xiao M., Whitnall M.H. Pharmacological countermeasures for the acute radiation syndrome. Curr. Mol. Pharmacol. 2009. Vol. 2, pp. 122-133.

19. Поиск противолучевых препаратов на модели пролонгированного облучения мышей с низкой мощностью дозы и оценка их влияния на экспрессию генов белков теплового шока / Рождественский Л.М., Михайлов В.Ф., Шлякова Т.Г., Шагирова Ж.М., Щеголева Р.А., Раева Н.Ф., Лисина Н.И., Шуленина Л.В., Зорин В.В., Пчелка А.В., Трубицина К.Ю. // Радиационная биология. Радиоэкология. 2015. № 4. С. 420-430.

20. Singh V.K., Romaine P.L., Seed T.M. Medical countermeasures for radiation exposure and related injuries // Health Phys. 2015. Vol. 108, pp. 607-630. 
21. Manda K., Ueno M., Moritake T., Anzai K. $\alpha$-Lipoic acid attenuates X-irradiation induced oxidative stress in mice // Cell Biol. Toxicol. 2007. Vol. 23, no. 2, pp. 129-137.

22. Оценка генотоксичности тетрахлорметана и защитного действия силибинина и хаурантина с помощью метода ДНК-комет в печени крыс / Кропотов А.В., Челомин В.П., Слободскова В. В., Солодова Е.Е., Михайлов А.О. // Тихоокеанский медицинский журнал. 2013. № 2. С. 63-66.

\section{References}

1. Baranov A.E., Rozhdestvensky L.M. Analiticheskiy obzor skhem lecheniya ostroy luchevoy bolezni, ispol'zuyemykh v eksperimente i klinike [Analytical review of the treatment regimens for acute radiation sickness used in the experiment and clinic]. Radiatsionnaya biologiya. Radioekologiya [Radiation Biology. Radioecology], 2008, vol. 48, no. 3, pp. 287-302.

2. Grebenyuk A.N., Zatsepin V.V., Aksenova N.V., Nazarov V.B., Vlasenko T.N. Modifikatsiya radiatsionnykh effektov vliyaniye posledovatel'nogo primeneniya preparata B-190 i interleykina-1b na vyzhivayemost' i kostnomozgovoye krovetvoreniye obluchennykh myshey [Modification of radiation effects the effect of sequential use of preparation B-190 and interleukin- $1 \beta$ on the survival and bone marrow hematopoiesis of irradiated mice]. Meditsina katastrof [Emergency Medicine], 2011, no. 4, pp. 475-480.

3. Rozhdestvenskiy L.M. Aktual'nyye voprosy poiska i issledovaniya protivoluchevykh sredstv [Topical issues of search and research of antiradiation means]. Radiatsiya i risk [Radiation and risk], 2013, no. 5, pp. 513-520.

4. Patil S.L., Mallaiah S.H., Patil R.K. Antioxidative and radioprotective potential of rutin and quercetin in swiss albino mice exposed to gamma radiation. $J$. Med. Phys., 2013, vol. 38, pp. 87-92.

5. Wang Y., Liu L., Pazhanisamy S.K., Li H., Meng A., Zhou D. Total body irradiation causes residual bone marrow injury by induction of persistent oxidative stress in murine hematopoietic stem cells. Free Radic. Biol. Med., 2010, vol. 48, pp. 348-356.

6. Browman K., Leong K.W. Chitosan nanoparticles for oral drug and gene delivery. Int. J. Nanomedicine, 2006, no. 2, pp. 17-28.

7. Abramova L.S., Deyev L.I., Kudryashov Yu. B., Kudryashova N. Yu., Parkhomenko I. M., Platonov A.G. Vozmozhnosti ispol'zovaniya zashchitnogo deystviya preparata MIGI-K v usloviyakh zagryazneniya mestnosti radionuklidami [Possibilities of using the protective effect of the MIGI-K preparation in conditions of contamination of the terrain with radionuclides]. Radiatsionnaya biologiya. Radioekologiya [Radiation Biology. Radioecology], 2011, vol. 51, no. 4, pp. 457-463.

8. Yan'kova V.I., Knyshova V.V., Lankin V.Z. Mekhanizmy korrektsii okislitel'nogo stressa antioksidantami iz morskikh gidrobiontov pri alimentarnykh dislip- 
idemiyakh [Mechanisms of correction of oxidative stress by antioxidants from marine hydrobionts in alimentary dyslipidemia]. Byulleten'SO RAMN [Bulletin of the SB RAMS], 2012, no. 1, pp. 64-69.

9. Dobryakov Yu.I., Dobryakov Ye.Yu., Ponomareva T.I. Issledovaniye farmakologicheskikh svoystv ekstrakta iz morskogo gidrobionta - astsidii purpurnoy (Halocynthia aurantium) [Study of the pharmacological properties of the extract from the marine hydrobiont - ascidian purpurea (Halocynthia aurantium)]. Dal'nevostochnyye morya Rossii [Far East sea of Russia]. Moscow: Nauka Publ., 2007, book 2, pp. 637-657.

10. Dobryakov Ye.Yu. Farmakologicheskiye effekty ekstrakta iz tuniki astsidii Halocynthia aurantium [Pharmacological effects of the extract from the tunic of ascidia Halocynthia aurantium]. Vladivostok, 2004, 25 p.

11. Dolmatova L.S., Dolmatov I.Yu., Dobryakov Yu.I. Antioksidantnaya i biologicheskaya aktivnost' ekstraktov goloturii Eupentacta fraudatrix i astsidii Halocynthia aurantium [Antioxidant and biological activity of extracts of holothuria Eupentacta fraudatrix and ascidia Halocynthia aurantium]. Materyaly s"yezda Fitofarm-2004 [Materials of congress Phytopharm-2004]. Saint-Petersburg: Adaptogen Publ., 2004, pp. 85-88.

12. Motorya Ye.S., Pivnenko T.N., Gazha A.K., Ivanushko L.A., Vorontsov V.N., Sanina N.M. Issledovaniye immunomoduliruyushchey i membranotropnoy aktivnosti karotinoidov iz tuniki astsidii Halocynthia aurantium [Investigation of immunomodulating and membranotropic activity of carotenoids from tunic of ascidia Halocynthia aurantium]. Tikhookeanskiy meditsinskiy zhurnal [Pacific medical journal], 2009, no. 3, pp. 28-31.

13. Ponomareva T.I., Dobryakov Yu.I. Issledovaniye biologicheskoy aktivnosti ekstraktov morskikh gidrobiontov nepishchevogo ispol'zovaniya [Research of biological activity of extracts of sea hydrobionts of non-food use]. Vmire nauchnykh otkrytiy [In the world of scientific discoveries], 2011, no. 7.2, pp. 908-918.

14. Kushnerova N.F., Dobryakov Yu.I., Yan'kova V.I. Khimicheskiy sostav spirtovykh izvlecheniy iz tuniki astsidii purpurnoy Halocynthia aurantium [Chemical composition of alcohol extracts from the tunic of ascidia purpurea Halocynthia aurantium]. Valeologiya: Diagnostika sredstva i praktika obespecheniya zdorov'ya. [Valeology: Diagnostics of the remedy and the practice of providing health], Vladivostok: Dal'nauka Publ., 2000, pp. 151-155.

15. Rukovodstvo po gematologii [Manual on hematology] ed. A.I. Vorob'yev, Moscow: Meditsina Publ., 2002, 235 p.

16. Pereverzev A.Ye. Krovetvornyye koloniyeobrazuyushchiye kletki i fizicheskiye stress-faktory [Hemopoietic colony-forming cells and physical stress factors], Leningrad: Nauka Publ., 1986, 172 p. 
17. Deyama T., Nishibe S., Nakazawa Y. Constituents and pharmacological effects of Eucommia and Sibirian ginseng. Acta Pharmacol. Sinica, 2011, no. 12, pp. 10571070.

18. Xiao M., Whitnall M.H. Pharmacological countermeasures for the acute radiation syndrome. Curr. Mol. Pharmacol., 2009, vol. 2, pp. 122-133.

19. Rozhdestvenskiy L.M., Mikhaylov V.F., Shlyakova T.G., Shagirova Zh.M., Shchegoleva R.A., Rayeva N.F., Lisina N.I., Shulenina L.V., Zorin V.V., Pchelka A.V., Trubitsina K.Yu. Poisk protivoluchevykh preparatov na modeli prolongirovannogo oblucheniya myshey s nizkoy moshchnost'yu dozy i otsenka ikh vliyaniya na ekspressiyu genov belkov teplovogo shoka [The search for anti-radiation drugs on the model of prolonged irradiation of mice with low dose rate and the evaluation of their effect on the expression of heat shock protein genes]. Radiatsionnaya biologiya. Radioekologiya [Radiation Biology. Radioecology], 2015, no. 4, pp. 420-430.

20. Singh V.K., Romaine P.L., Seed T.M. Medical countermeasures for radiation exposure and related injuries Health Phys., 2015, vol. 108, pp. 607-630.

21. Manda K., Ueno M., Moritake T., Anzai K. $\alpha$-Lipoic acid attenuates X-irradiation induced oxidative stress in mice. Cell Biol. Toxicol., 2007, vol. 23, no. 2, pp. 129-137.

22. Kropotov A.V., Chelomin V.P., Slobodskova V. V., Solodova Ye.Ye., Mikhaylov A.O. Otsenka genotoksichnosti tetrakhlormetana i zashchitnogo deystviya silibinina i khaurantina s pomoshch'yu metoda DNK-komet v pecheni krys [Assessment of the genotoxicity of carbon tetrachloride and the protective effect of silybinin and haurantine using the method of DNA comets in rat liver]. Tikhookeanskiy meditsinskiy zhurnal [Pacific Medical Journal], 2013, no. 2, pp. 63-66.

\section{ДАННЫЕ ОБ АВТОРЕ}

Пономарева Татьяна Ивановна, старший научный сотрудник, кандидат биологических наук Тихоокеанский океанологический институт им. В.И. Ильичева ул. Балтийская, 43, г. Владивосток, 690041, Российская Федераџия pti.50@yandex.ru

\section{DATA ABOUT THE AUTHOR}

Ponomareva Tatiana Ivanovna, Doctor of Biological Science, Senior Researcher

V.I. Il'ichev Pacific Oceanological Institute

43, Baltiyskaya Str., Vladivostok, 690041, Russian Federation pti.50@yandex.ru 